\title{
The Atmospheric Pathway of the Cloud-Radiative Impact on the Circulation Response to Global Warming: Important and Uncertain
}

\author{
AIKO VOIGT \\ Institute of Meteorology and Climate Research-Department Troposphere Research, Karlsruhe Institute of Technology, Karlsruhe, \\ Germany, and Lamont-Doherty Earth Observatory, Columbia University, Palisades, New York \\ Nicole Albern and Georgios Papavasileiou \\ Institute of Meteorology and Climate Research-Department Troposphere Research, Karlsruhe Institute of Technology, Karlsruhe, \\ Germany
}

(Manuscript received 27 November 2018, in final form 21 February 2019)

\begin{abstract}
Previous work showed that the poleward expansion of the annual-mean zonal-mean atmospheric circulation in response to global warming is strongly modulated by changes in clouds and their radiative heating of the surface and atmosphere. Here, a hierarchy and an ensemble of global climate models are used to study the circulation impact of changes in atmospheric cloud-radiative heating in the absence of changes in sea surface temperature (SST), which is referred to as the atmospheric pathway of the cloud-radiative impact. For the MPI-ESM model, the atmospheric pathway is responsible for about half of the total cloud-radiative impact, and in fact half of the total circulation response. Changes in atmospheric cloud-radiative heating are substantial in both the lower and upper troposphere. However, because SST is prescribed the atmospheric pathway is dominated by changes in upper-tropospheric cloud-radiative heating, which in large part results from the upward shift of high-level clouds. The poleward circulation expansion via the atmospheric pathway and changes in upper-tropospheric cloud-radiative heating are qualitatively robust across three global models, yet their magnitudes vary by a factor of 3 . A substantial part of these magnitude differences are related to the upper-tropospheric radiative heating by high-level clouds in the present-day climate. A comparison with observations highlights the model deficits in representing the radiative heating by high-level clouds and indicates that reducing these deficits can contribute to improved predictions of regional climate change.
\end{abstract}

\section{Introduction}

Regional climate is determined by the planetary redistribution of energy, momentum, and moisture by the large-scale circulation of the atmosphere. Anticipating regional climate change thus relies on understanding the response of the atmospheric circulation to increasing greenhouse gases (Shepherd 2014; Collins et al. 2018). One circulation response that is robustly predicted by global climate models is a poleward expansion of the circulation. The expansion manifests in poleward shifts of the extratropical jet streams and storm tracks (Yin 2005; Barnes and Polvani 2013), poleward shifts of the edges of the tropical Hadley circulation (Seidel et al. 2008), and a poleward expansion of the subtropical dry zones (Scheff and Frierson 2012). Recent modeling

Corresponding author: Aiko Voigt, aiko.voigt@kit.edu work demonstrated that the poleward expansion is strongly modulated by cloud-radiative interactions, which heat (or cool) the atmosphere and surface (Voigt and Shaw 2015, 2016; Ceppi and Hartmann 2016; Ceppi and Shepherd 2017; Li et al. 2019). Here, we build upon the previous aquaplanet modeling work of Voigt and Shaw $(2015,2016)$ and demonstrate the importance of, and the uncertainty in, cloud-radiative heating inside the atmosphere by comparing three global climate models using the cloud-locking method.

The cloud-radiative impact on the circulation response to global warming arises from the fact that as Earth warms, clouds change their location, fraction, and liquid and ice condensate. This change in cloudradiative properties (i.e., cloud albedo, optical thickness, and emissivity) leads to regional changes of cloud-radiative heating inside the atmosphere and at the surface that alter horizontal and vertical temperature 
gradients, and as a result the circulation. Theories of the atmospheric circulation and climate models of various complexity suggest that an increase in tropical stability leads to a poleward circulation expansion (e.g., Schneider 2006; Lu et al. 2007; Butler et al. 2010). An increase in upper-level and lower-level meridional temperature gradients likewise leads to a wider Hadley cell and poleward shift of the extratropical jets, which can be related to changes in the growth rate, the characteristics, and the breaking of extratropical baroclinic eddies (e.g., Chen and Held 2007; Kidston et al. 2011; Voigt and Shaw 2016). The temperature response to global warming is of course affected by more than clouds. Yet, because clouds are inhomogeneous in space, they appear to be particularly effective in creating temperature gradients. In fact, the radiative coupling of clouds with the circulation is so fundamental that it has been identified as a grand challenge of current climate research (Bony et al. 2015).

We find it helpful to separate the cloud-radiative impact on the circulation into two pathways. We define the two pathways in analogy to the slow (surface temperature mediated) and fast (no surface temperature change) circulation response to changes in $\mathrm{CO}_{2}$, aerosol, or ozone (Deser and Phillips 2009; Bony et al. 2013; Voigt et al. 2017). The first pathway operates via the surface component of the cloud-radiative heating and the surface energy balance. Because the equilibrium surface energy balance must be closed, changes in the surface cloud-radiative heating lead to changes in surface temperatures. We refer to this first pathway as the surface pathway. Although the surface pathway can involve changes in global-mean surface temperature, previous work found it to predominantly act via changes in surface temperature gradients (Ceppi and Hartmann 2016; Ceppi and Shepherd 2017). The second pathway operates via changes in atmospheric cloud-radiative heating and the atmospheric energy balance. Changes in atmospheric cloud-radiative heating lead to temperature changes inside the atmosphere that affect the circulation even in the absence of surface temperature changes. Although the cloud changes themselves would not occur without surface temperature changes (apart from rapid adjustments; Zelinka et al. 2013), the separation into the atmospheric and surface pathways allows one to disentangle the role of atmospheric and surface cloud-radiative heating.

Previous work by Ceppi et al. (2014), Ceppi and Hartmann (2016), and Ceppi and Shepherd (2017) emphasized the role of the surface pathway and found that extratropical low-level mixed-phase clouds, which cool extratropical SST by shortwave cloud changes, amplify the circulation expansion. Ceppi and Hartmann (2016) found no circulation impact from longwave cloud changes because extratropical SST warming from the surface pathway and upper-tropospheric tropical warming from the atmospheric pathway compensated in their model. The atmospheric pathway has been investigated in idealized aquaplanet (no continent) setups (Voigt and Shaw 2015, 2016) and recently also in realistic model setups (with continents, etc.) from the Clouds On-Off Klimate Intercomparion Experiment (COOKIE) model intercomparison project (Stevens et al. 2012) with transparent clouds (Li et al. 2019). This work showed that 1) in aquaplanet setups the atmospheric pathway contributes about half of the total circulation expansion in response to a uniform increase in sea surface temperature, and 2) the cloud-radiative impact results from changes in tropical and midlatitude high-level clouds, which under global warming shift upward and create an anomalous cloud-radiative heating in the tropical and midlatitude upper troposphere. However, it is difficult to quantify the magnitude of the atmospheric pathway from COOKIE simulations because of the cloud impact on the presentday circulation ( $\mathrm{Li}$ et al. 2019). Also, it remains unclear which aspects of the atmospheric pathway are robust across models, and how important the atmospheric pathway is compared to the surface pathway.

The atmospheric circulation, and the extratropical circulation in particular (Shaw et al. 2016), is affected by many factors that can work in cooperation or oppose each other. Many of these factors (e.g., sea ice, stationary waves, and changes in SST gradients) are omitted in aquaplanet simulations. It is necessary to test to what extent the results from aquaplanet simulations are relevant for future changes in Earth's atmospheric circulation, and to what extent the cloud-radiative impact is modulated by other factors. In this paper, we therefore extend the aquaplanet work of Voigt and Shaw (2015) and Voigt and Shaw (2016) and use simulations with three global models in realistic model setups that include continents, sea ice, a seasonal cycle, and so on. We address robust and non-robust aspects of the atmospheric pathway, and quantify the importance of the atmospheric pathway relative to the surface pathway. Throughout the paper, we focus on the annual-mean zonal-mean circulation.

The paper is organized as follows. In section 2 we describe the circulation metrics that we use to characterize the circulation expansion. We also briefly summarize the cloud-locking method, which we use to determine the cloud-radiative impact. In section 3 we quantify the total cloud-radiative impact and the contribution of the atmospheric pathway using the MPIESM model. We find that, at least in MPI-ESM, almost 
TABLE 1. Shifts in the position of the extratropical jet ( $\left({ }^{\circ}\right.$ latitude). The first number is for the Southern Hemisphere $\left({ }^{\circ} \mathrm{S}\right)$ and the second for the Northern Hemisphere $\left({ }^{\circ} \mathrm{N}\right)$. For both hemispheres, positive numbers indicate a poleward shift. The noncloud contribution plotted in the figures is the sum of the contributions from SST/CO $\mathrm{CO}_{2}$ and water vapor. Note that in MPI-ESM SSTSLAB the cloud contribution is solely due to the atmospheric pathway, and the surface pathway of the cloud-radiative impact active in SLAB is shifted to SST/CO 2 and water vapor. Likewise, the cloud contribution in all SST4K simulations is only due to the atmospheric pathway. The residual in the rightmost column is the difference between the total change and the sum of cloud, $\mathrm{SST} / \mathrm{CO}_{2}$, and water vapor contributions.

\begin{tabular}{lllllrr}
\hline \hline \multicolumn{1}{c}{ Model } & Setup & Total & Clouds & SST/CO & Water vapor & Residual \\
\hline MPI-ESM & SLAB & $3.2,2.4$ & $3.1,2.7$ & $0.9,1.4$ & $-0.9,-0.9$ & $-0.0,-0.7$ \\
& SSTSLAB & $2.3,3.1$ & $1.4,2.2$ & $2.2,2.2$ & $-1.1,-0.7$ & $-0.2,-0.6$ \\
IPSL-CM5A & SST4K & $2.4,1.2$ & $1.3,0.6$ & $2.1,0.4$ & $-0.9,-0.4$ & $-0.1,0.5$ \\
ICON & SST4K & $1.8,1.4$ & $3.3,1.8$ & $0.5,-0.5$ & $-1.1,-0.1$ & $-0.9,0.2$ \\
\hline
\end{tabular}

all of the poleward circulation expansion in response to global warming can be attributed to cloud-radiative changes [consistent with Ceppi and Shepherd (2017)], and that half of the cloud-radiative impact arises from the atmospheric pathway. In section 4 , we analyze simulations from three models, MPI-ESM, IPSL-CM5A, and Icosahedral Non-hydrostatic model (ICON), with prescribed SST and global warming mimicked by a uniform 4-K SST increase. We find that the atmospheric pathway is largely independent of the pattern of surface warming and that changes in atmospheric cloud-radiative heating scale with global-mean surface warming. We further find that the atmospheric pathway leads to a poleward circulation expansion in all three models, but that its magnitude varies by a factor of 3 between the models. In section 5 we focus on changes in upper-tropospheric cloud-radiative heating, and highlight model deficits in representing the radiative heating of high-level tropical and midlatitude clouds by comparing to observational and reanalysis data from CloudSat/CALIPSO and ERA-Interim. The paper concludes in section 6 .

\section{Circulation metrics, cloud-locking method, and diagnostic of changes in cloud-radiative heating}

\section{a. Circulation metrics}

We characterize the annual-mean zonal-mean circulation in terms of the tropical Hadley circulation, the subtropical latitude of zero net precipitation $(P-E=0)$, and the extratropical eddy-driven jet. The poleward edges of the Hadley cells are defined as the subtropical latitudes at which the mass streamfunction at $500 \mathrm{hPa}$ changes sign. The position of the extratropical jet is calculated as the latitude at which the $850-\mathrm{hPa}$ zonal wind is maximum. To remove the impact of the model grid, we perform a quadratic fit to the five grid points around the latitude of maximum zonal wind (Barnes and Polvani 2013). The circulation metrics are listed in Tables 1-3.

\section{b. Cloud-locking method}

To diagnose the circulation impact of cloud-radiative changes, we use the cloud-locking method (Mauritsen et al. 2013; Voigt and Shaw 2015). We lock the radiative properties of clouds (cloud cover, liquid, and ice) and water vapor (specific humidity). Because the paper focuses on clouds, we refer to the method in short form as the cloud-locking method. In a first step, the radiative properties of clouds and water vapor are diagnosed from the present-day and the global-warming simulations. The difference between the two simulations defines the total circulation response to global warming, denoted by $\Delta X$. Then, eight additional simulations are performed in which $\mathrm{CO}_{2}$ and/or SST (depending on whether interactive or prescribed SSTs are used) as well as the radiative properties of clouds and water vapor are "locked" to either the present-day simulation or the global-warming simulation. Surface albedo is not locked in our simulations. Ceppi and Shepherd (2017) found that surface albedo has a negligible impact on the circulation expansion in MPI-ESM simulations with interactive SST. For simulations with prescribed SST, sea ice is prescribed, which strongly limits changes in surface albedo.

Based on the eight locked simulations, we decompose the circulation response to global warming into contributions from changes in $\mathrm{SST} / \mathrm{CO}_{2}$, cloud-radiative properties, and water vapor radiative properties. The cloud-radiative impact is computed as

$$
\begin{aligned}
\Delta X_{\text {cloud }}= & \frac{1}{4}\left[\left(X_{\mathrm{F} 1 \mathrm{C} 2 \mathrm{~W} 1}-X_{\mathrm{F} 1 \mathrm{C} 1 \mathrm{~W} 1}\right)+\left(X_{\mathrm{F} 1 \mathrm{C} 2 \mathrm{~W} 2}-X_{\mathrm{F} 1 \mathrm{C} 1 \mathrm{~W} 2}\right)\right. \\
& \left.+\left(X_{\mathrm{F} 2 \mathrm{C} 2 \mathrm{~W} 1}-X_{\mathrm{F} 2 \mathrm{C} 1 \mathrm{~W} 1}\right)+\left(X_{\mathrm{F} 2 \mathrm{C} 2 \mathrm{~W} 2}-X_{\mathrm{F} 2 \mathrm{C} 1 \mathrm{~W} 2}\right)\right],
\end{aligned}
$$

where the subscripts indicate that $\mathrm{SST} / \mathrm{CO}_{2}(\mathrm{~F})$, clouds (C), and water vapor (W) are locked to the present-day or the global-warming simulation (denoted by 1 and 2 , respectively). The radiative impact of water vapor changes $\Delta X_{\text {vap }}$ is computed analogously. The impact of 
TABLE 2. Shifts in the subtropical latitude of zero net precipitation $\left({ }^{\circ}\right.$ latitude). The first number is for the Southern Hemisphere $\left({ }^{\circ} \mathrm{S}\right)$ and the second for the Northern Hemisphere $\left({ }^{\circ} \mathrm{N}\right)$. For both hemispheres, positive numbers indicate a poleward shift. The noncloud contribution plotted in the figures is the sum of the contributions from SST/CO $\mathrm{C}_{2}$ and water vapor. Note that in MPI-ESM SSTSLAB the cloud contribution is solely due to the atmospheric pathway, and the surface pathway of the cloud-radiative impact active in SLAB is shifted to $\mathrm{SST} / \mathrm{CO}_{2}$ and water vapor. Likewise, the cloud contribution in all SST4K simulations is only due to the atmospheric pathway. The residual in the rightmost column is the difference between the total change and the sum of cloud, SST/CO $\mathrm{CO}_{2}$ and water vapor contributions.

\begin{tabular}{clccccc}
\hline \hline \multicolumn{1}{c}{ Model } & Setup & Total & Clouds & SST/CO & Water vapor & Residual \\
\hline MPI-ESM & SLAB & $1.6,1.7$ & $1.0,1.1$ & $0.5,0.4$ & $0.1,0.1$ & $-0.1,0.0$ \\
& SSTSLAB & $1.4,1.7$ & $0.7,0.7$ & $0.9,1.5$ & $0.0,-0.2$ & $-0.2,-0.3$ \\
& SST4K & $1.2,1.1$ & $0.4,0.6$ & $0.8,1.0$ & $0.0,-0.2$ & $-0.1,-0.3$ \\
IPSL-CM5A & SST4K & $1.4,1.0$ & $0.6,0.3$ & $0.8,0.7$ & $-0.1,-0.0$ & $0.1,0.0$ \\
ICON & SST4K & $1.1,1.4$ & $0.3,0.4$ & $0.8,1.5$ & $0.1,-0.2$ & $-0.1,-0.3$ \\
\hline
\end{tabular}

$\mathrm{SST} / \mathrm{CO}_{2}$ changes in the absence of radiative changes in clouds and water vapor is computed as

$$
\begin{aligned}
\Delta X_{\mathrm{SST} / \mathrm{CO}_{2}}= & \frac{1}{2}\left[\left(X_{\mathrm{F} 2 \mathrm{C} 1 \mathrm{~W} 1}-X_{\mathrm{F} 1 \mathrm{C} 1 \mathrm{~W} 1}\right)\right. \\
& \left.+\left(X_{\mathrm{F} 2 \mathrm{C} 2 \mathrm{~W} 2}-X_{\mathrm{F} 2 \mathrm{C} 1 \mathrm{~W} 1}\right)\right] .
\end{aligned}
$$

By construction, the three contributions sum up to the total "locked" response:

$$
\Delta X_{\text {lock }}=\Delta X_{\text {cloud }}+\Delta X_{\text {vap }}+\Delta X_{\mathrm{SST} / \mathrm{CO} 2} .
$$

Because we focus on clouds, most figures show the sum of the contribution from changes in $\mathrm{SST} / \mathrm{CO}_{2}$ and water vapor $\Delta X_{\mathrm{SST} / \mathrm{CO} 2}+\Delta X_{\text {vap }}$ to which we refer as the noncloud contribution.

The total locked response $\Delta X_{\text {lock }}$ can deviate from the total response $\Delta X$. That is,

$$
\Delta X=\Delta X_{\text {lock }}+\Delta X_{\text {res }} \text {. }
$$

The residual term arises because the locking method decorrelates the radiative properties of clouds and water vapor from the instantaneous circulation, such as when the radiative properties of cold-sector clouds are prescribed in the warm sector of an extratropical cyclone. The residual term is included in the figures and tables and is found to be small compared to the total circulation response to global warming.

\section{c. Diagnostic of changes in cloud-radiative heating}

The cloud response to global warming leads to changes in cloud-radiative heating. We diagnose these radiative heating changes by means of partial-radiative perturbation calculations, which are offline radiative transfer calculations with clouds prescribed to the present-day and the global-warming climate, respectively (Wetherald and Manabe 1988; Colman and McAvaney 1997). The calculations provide changes in cloud-radiative heating inside the atmosphere $\left(\mathrm{K} \mathrm{day}^{-1}\right)$, at the surface $\left(\mathrm{W} \mathrm{m}^{-2}\right)$, and at the top of the atmosphere $\left(\mathrm{W} \mathrm{m}^{-2}\right)$. For ease of computation, we use forward calculations that contrast the radiative fluxes and heating rates of the present-day climate with a radiative calculation for which cloud-radiative properties are prescribed to the global-warming climate, while all other variables remain at the present-day climate. We have verified for the MPI-ESM model with interactive SST that the forward calculation agrees well with a twosided calculation: the two calculations differ by less than $0.1 \mathrm{~K} \mathrm{day}^{-1}$ in terms of diagnosed changes in atmospheric cloud-radiative heating (see also Voigt and Shaw 2016). These diagnostic differences are negligible compared to the strong model differences in changes of

TABLE 3. Shifts in the edge of the Hadley cells ( ${ }^{\circ}$ latitude). The first number is for the Southern Hemisphere $\left({ }^{\circ} \mathrm{S}\right)$ and the second for the Northern Hemisphere $\left({ }^{\circ} \mathrm{N}\right)$. For both hemispheres, positive numbers indicate a poleward shift. The noncloud contribution plotted in the figures is the sum of the contributions from SST/CO $/ \mathrm{C}_{2}$ and water vapor. Note that in MPI-ESM SSTSLAB the cloud contribution is solely due to the atmospheric pathway, and the surface pathway of the cloud-radiative impact active in SLAB is shifted to SST/CO vapor. Likewise, the cloud contribution in all SST4K simulations is only due to the atmospheric pathway. The residual in the rightmost column is the difference between the total change and the sum of cloud, SST/CO

\begin{tabular}{lllllrr}
\hline \hline \multicolumn{1}{c}{ Model } & Setup & Total & Clouds & SST/CO & Water vapor & Residual \\
\hline MPI-ESM & SLAB & $2.3,1.7$ & $1.5,1.5$ & $0.6,0.4$ & $0.3,0.0$ & $-0.1,-0.1$ \\
& SSTSLAB & $2.0,1.7$ & $1.1,1.1$ & $1.0,0.7$ & $0.0,0.1$ & $0.0,-0.2$ \\
& SST4K & $2.0,1.2$ & $0.8,0.7$ & $1.2,0.5$ & $-0.1,-0.1$ & $0.2,0.2$ \\
IPSL-CM5A & SST4K & $1.5,0.8$ & $1.3,0.8$ & $0.6,-0.1$ & $-0.3,-0.1$ & $-0.1,0.1$ \\
ICON & SST4K & $2.0,2.7$ & $0.8,1.5$ & $1.5,3.5$ & $-0.1,-1.0$ & $-0.2,-1.4$ \\
\hline
\end{tabular}


cloud-radiative heating that we will discuss in sections 4 and 5. The calculations are done for 15 years for the MPI-ESM model with interactive SST, and for at least 5 years for all models with prescribed SST. The partialradiative perturbation calculations are done with the models' own radiative transfer schemes. The same diagnostic was used in the aquaplanet work of Voigt and Shaw (2016), who used the term "cloud-radiative forcing.' For better clarity, we here instead use the term "changes in cloud-radiative heating."

\section{The total cloud-radiative impact and the contribution from the atmospheric pathway in the MPI-ESM model}

We start with quantifying the total cloud-radiative impact (i.e., the sum of the atmospheric and surface pathways). To this end, we perform interactive SST simulations with the atmospheric component of the MPIESM model (ECHAM6 version 6.1.00p1; Giorgetta et al. 2013; Stevens et al. 2013), and with global warming triggered by quadrupled $\mathrm{CO}_{2}$. SSTs are made interactive by coupling to a 50-m-deep thermodynamic slab ocean. The $q$ flux representing ocean energy transport is diagnosed from a present-day simulation in which SST and sea ice are prescribed to the 1979-2008 CMIP5 AMIP climatology (Taylor et al. 2012). We refer to this set of simulations as SLAB.

We use the CMIP5 low-resolution (LR) version with spectral truncation T63 (corresponding to $1.875^{\circ}$ latitude $\times 1.875^{\circ}$ longitude) and 47 levels extending up to $0.01 \mathrm{hPa}$. For the present-day simulation, well-mixed greenhouse gases are set to the 1979-2008 average $\left(\mathrm{CO}_{2}=359\right.$ ppmv, $\mathrm{CH}_{4}=1693$ ppbv, $\mathrm{N}_{2} \mathrm{O}=311$ ppbv, $\mathrm{CFC}_{11}=237$ pptv, $\mathrm{CFC}_{12}=462$ pptv, where pptv is parts per trillion by volume), monthly ozone is set to the 1979-2008 climatology, and aerosol is specified from year 2000 of the Max Planck Institute Aerosol Climatology (MAC; Kinne et al. 2013), neglecting stratospheric aerosol of volcanic origin. Orbital parameters are set to time-constant present-day values with a global-mean annual-mean total solar irradiance of $1362 \mathrm{~W} \mathrm{~m}^{-2}$. The slabocean simulations are run for 40 years, with the first 15 years excluded from the analysis to remove spinup effects.

Figure 1a shows the total circulation response to quadrupled $\mathrm{CO}_{2}$ in the interactive-SST setup of MPIESM. In the global mean, the surface warms by $7.7 \mathrm{~K}$, a value typical for current global climate models (Vial et al. 2013). The troposphere warms everywhere, with peak warming in the tropical upper troposphere, as expected from increased atmospheric water vapor and latent heat release (Stevens and Bony 2013), and in the Arctic lower troposphere, a phenomenon known as
Arctic amplification (Pithan and Mauritsen 2014). The stratosphere cools due to increased stratospheric $\mathrm{CO}_{2}$ and water vapor. This strengthens the meridional temperature gradient and zonal winds in the tropical and midlatitude upper troposphere and lower stratosphere. In the middle and lower troposphere, the zonal wind change is characterized by a dipole of anomalous easterlies around $30^{\circ} \mathrm{N} / \mathrm{S}$ and anomalous westerlies around $60^{\circ} \mathrm{N} / \mathrm{S}$, signaling a poleward shift of the extratropical jet streams and Hadley cell edges in both hemispheres by about $2^{\circ}-3^{\circ}$ of latitude (Tables 1 and 3; black line in Fig. 1d). Likewise, the subtropical dry zones expand poleward by almost $2^{\circ}$ of latitude (Table 2 ), as is evident from the decrease in net precipitation around $30^{\circ}-45^{\circ} \mathrm{N} / \mathrm{S}$ (precipitation minus evaporation; black line in Fig. 1f). The temperature and circulation changes shown in Fig. 1 are typical for, and in the range of, global climate model projections (Barnes and Polvani 2013; Grise and Polvani 2016).

Cloud-radiative changes are fundamental for the circulation response to global warming. To show this, Fig. 1 and Tables 1-3 include the noncloud contribution and the contribution from cloud-radiative changes, which we quantify by means of the cloud-locking method. A similar analysis with MPI-ESM in a slab ocean setup was presented in Ceppi and Shepherd $(2017)^{1}$ — it is repeated here to lay the basis for our study of the atmospheric pathway. In the global mean, cloud-radiative changes contribute less than $10 \%(0.7 \mathrm{~K})$ to the global-mean surface warming of $7.7 \mathrm{~K}$, and contribute little to the magnitude of surface and tropospheric warming. Yet, although cloud-radiative changes have little impact on surface temperature, they dominate the circulation expansion. Most of the dipole response of the extratropical zonal winds and the poleward shift of the extratropical jet streams is attributed to clouds. In fact, without cloudradiative changes the extratropical jet streams would change little, if at all. Cloud-radiative changes support the expansion of the subtropical dry zones by decreasing net precipitation around $40^{\circ} \mathrm{N} / \mathrm{S}$ and play a leading role for the expansion of the Hadley circulation. The dominant role of cloud-radiative changes for the circulation expansion in the MPI-ESM model is consistent with slab-ocean simulations with CAM4 (Ceppi and Shepherd 2017), and with GFDL AM2.1 in aquaplanet setup (Ceppi and Hartmann 2016).

The dominance of cloud-radiative changes can be understood from the temperature response. The cloud

\footnotetext{
${ }^{1}$ Ceppi and Shepherd (2017) also locked the surface albedo, which they found to have a negligible impact on the expansion of the annual-mean zonal-mean circulation.
} 

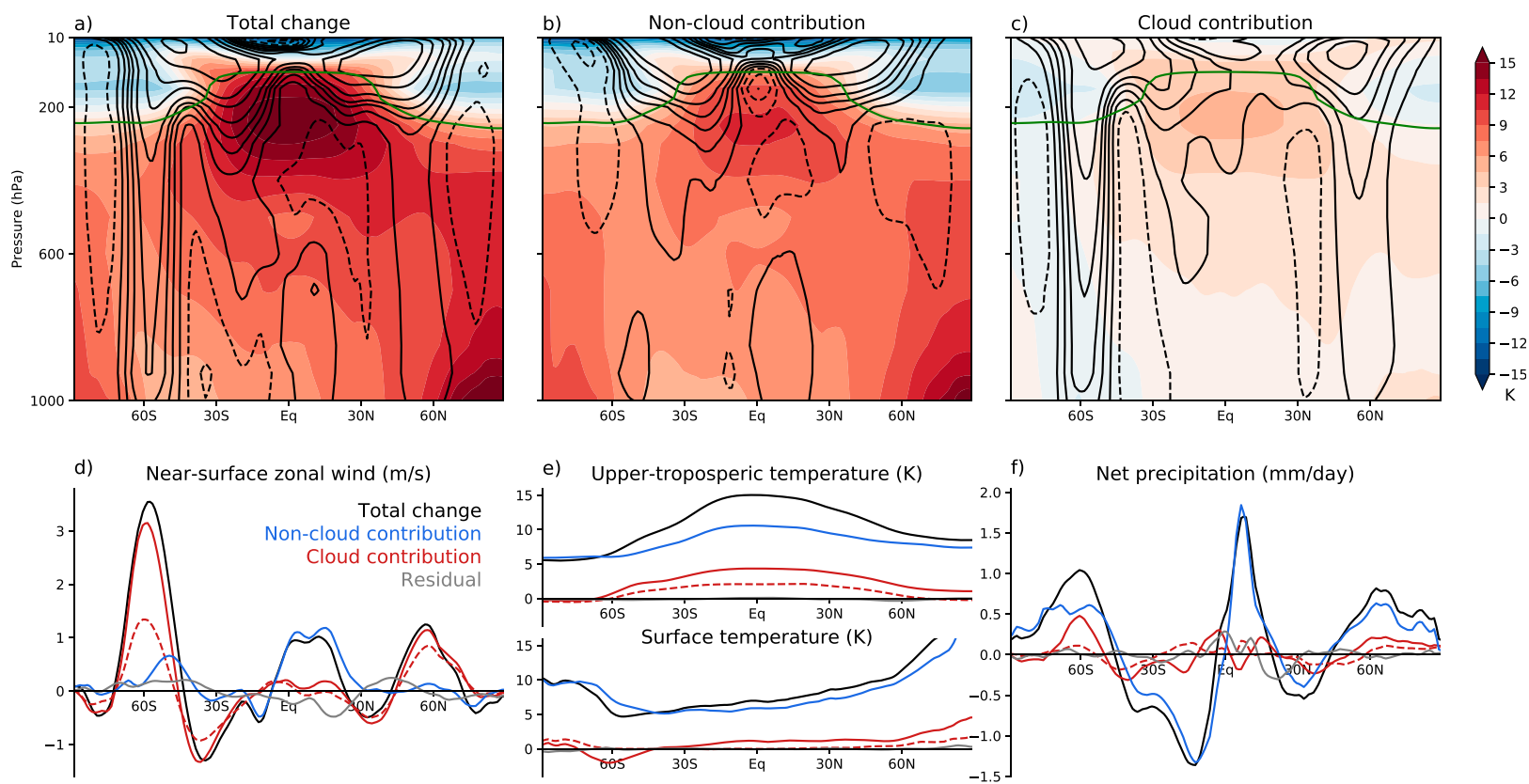

FIG. 1. Circulation response to quadrupled $\mathrm{CO}_{2}$ in the MPI-ESM model: (a) total change in temperature and zonal wind, (b) temperature and zonal wind change attributed to the sum of $\mathrm{CO}_{2}$ increase and water vapor changes in the absence of cloud changes (noncloud contribution), and (c) temperature and zonal wind change attributed to cloud changes. The temperature change is shown in colors and the wind change by the dashed (negative change) and solid (positive change) black lines, with contour intervals of $1 \mathrm{~m} \mathrm{~s}^{-1}$ between 0 and $3.5 \mathrm{~m} \mathrm{~s}^{-1}, 2 \mathrm{~m} \mathrm{~s}^{-1}$ between 5 and $10 \mathrm{~m} \mathrm{~s}^{-1}$, and $5 \mathrm{~m} \mathrm{~s}^{-1}$ for wind changes with a magnitude larger than $10 \mathrm{~m} \mathrm{~s}^{-1}$. The green lines in (a)-(c) depict the present-day temperature tropopause. Also shown are (d) change in near-surface zonal wind at $850 \mathrm{hPa}$, (e) change in upper-tropospheric $(300 \mathrm{hPa})$ and surface temperature, and (f) change in net precipitation. The dashed red line measures the atmospheric pathway of the cloud contribution.

contribution to the absolute temperature change is small, yet clouds amplify the meridional temperature gradient and baroclinicity throughout the whole depth of the troposphere. Clouds lead to distinct warming of the upper troposphere in the tropics and midlatitudes, and distinct cooling of the lower troposphere around $60^{\circ} \mathrm{S}$ (Figs. 1c,e). This increases the equator-to-pole temperature gradient at lower and upper levels and allows for a strong circulation response. For the noncloud contribution, the situation is different. The noncloud contribution leads to distinct warming of the upper troposphere in the tropics and midlatitudes as well as distinct warming of the lower troposphere in high latitudes. Thus, the meridional temperature gradient is increased at upper levels but decreased at lower levels, resulting in a small circulation response (Shaw et al. 2016). In summary, although cloud changes contribute little to the magnitude of global warming, they dominate the circulation response by increasing the meridional temperature gradient and baroclinicity in both the upper and the lower troposphere.

The cloud-induced temperature response is tied to changes in cloud-radiative heating. These are shown in Fig. 2. At the top of the atmosphere (TOA) and in the global mean, changes in cloud-radiative heating are small compared to changes in radiative heating from increased carbon dioxide and water vapor (7.1 vs $27.6 \mathrm{~W} \mathrm{~m}^{-2}$ ). This is in line with the minor impact of clouds on the magnitude of the global-mean warming. Yet, the changes in TOA cloud-radiative heating vary strongly with latitude (Fig. 2a). They are positive in low latitudes and negative in high latitudes, promoting an increase in baroclinicity. At the surface (Fig. 2c), changes in cloud-radiative heating are characterized by anomalous low-latitude heating and anomalous southern high-latitude cooling. This meridional pattern is dominated by the shortwave component, which works in favor of increased surface baroclinicity due to decreased subtropical low-level cloud fraction and more reflective high-latitude low-level mixed-phase clouds (Ceppi et al. 2017). There is also a substantial contribution from the longwave component, which compensates part of the surface shortwave changes. Changes in cloud-radiative heating are also substantial inside the atmosphere (Fig. 2b). Changes in atmospheric cloud-radiative heating arise mainly from the longwave component, reach values of up to $1 \mathrm{~K} \mathrm{day}^{-1}$, and also work in favor of increased atmospheric baroclinicity. The lower troposphere experiences anomalous low-latitude heating, consistent with the decrease in low-level clouds, and 

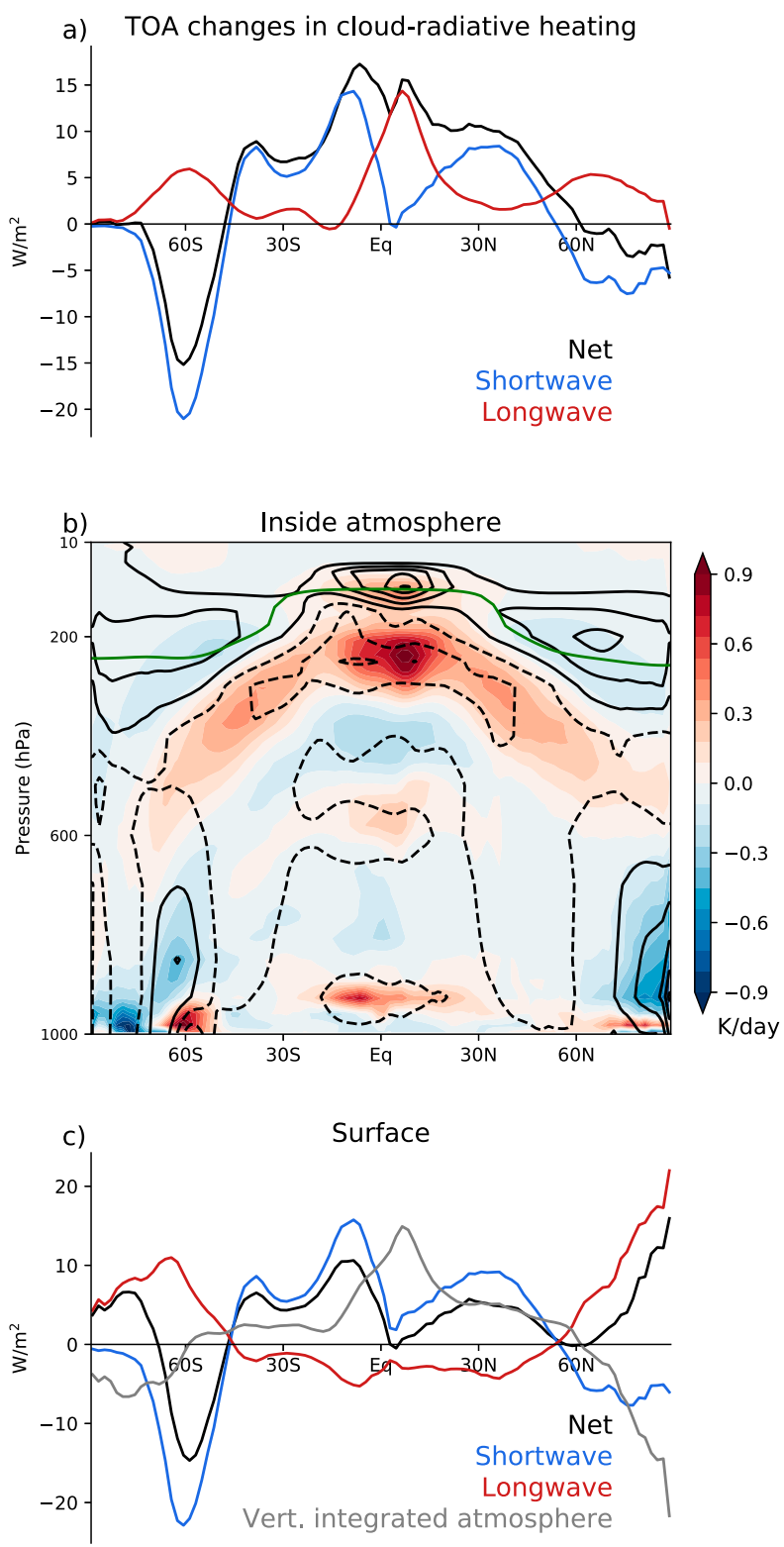

FIG. 2. Change in cloud-radiative heating under quadrupling of atmospheric $\mathrm{CO}_{2}$ in the MPI-ESM model for the SLAB simulations as diagnosed by a partial-radiative perturbation calculation: (a) at the top of the atmosphere (TOA); (b) inside the atmosphere in colors, with cloud-fraction change in black contours (contour intervals of $4 \%$, positive change shown as solid contours, negative change as dashed; the green line depicts the present-day temperature tropopause); and (c) at the surface. The vertical integral of changes in atmospheric cloud-radiative heating is shown in gray for comparison.

high-latitude heating near the surface and cooling above. In the upper troposphere, the most prominent feature is a broad arc of anomalous heating in the tropics and midlatitudes, with anomalous cooling above and below. To first order, changes in upper-tropospheric cloud-radiative heating can be viewed to result from the upward shift of high-level clouds (Mitchell and Ingram 1992; Zelinka et al. 2013; Voigt and Shaw 2016; Ceppi et al. 2017; Li et al. 2019), a robust and well-understood thermodynamic cloud response to global warming (Hartmann and Larson 2002; Thompson et al. 2017). An important role of the upward shift of high-level clouds in creating changes in upper-tropospheric cloud-radiative heating was also reported by Li et al. (2019) in COOKIE simulations. Sections 4 and 5 will discuss this point in more detail, and will show that changes in upper-tropospheric cloud-radiative heating are qualitatively robust across models, whereas changes in the lower-troposphere cloud-radiative heating are not robust.

We now study to what extent the total cloud-radiative impact arises from the atmospheric pathway. To this end, we juxtapose the SLAB simulations with prescribedSST simulations. SST and sea ice are prescribed to the SLAB climatologies of either the present-day or the $4 \times \mathrm{CO}_{2}$ climate. In the simulations with present-day SST and sea ice, $\mathrm{CO}_{2}$ is also set to the present-day value; in the simulations with $4 \times \mathrm{CO}_{2}$ SST and sea ice, $\mathrm{CO}_{2}$ is also quadrupled. We simulate at least 29 years and exclude the first year to remove spinup effects. To emphasize that SSTs are prescribed to the slab-ocean climatologies, we refer to these simulations as SSTSLAB. The total circulation response in SSTSLAB is very similar to that in SLAB (Tables 1-3; Fig. 3). The SSTLAB simulations disable the surface pathway and isolate the atmospheric pathway. The surface pathway is shifted to contributions from $\mathrm{CO}_{2}$ and water vapor changes, which increases the noncloud contribution in SSTSLAB compared to SLAB.

The cloud-radiative impact remains important in SSTSLAB. This demonstrates the importance of the atmospheric pathway and is shown in Figs. 1d-f by the red dashed lines and in Fig. 3, which compares circulation metrics for SLAB and SSTSLAB. The atmospheric pathway is responsible for about half of the total cloudradiative impact in terms of the extratropical zonal wind response and the decrease of net precipitation around $45^{\circ} \mathrm{N} / \mathrm{S}$ (Fig. 1). In terms of the circulation metrics, half or more of the total cloud-radiative impact, and in fact half or more of the total circulation response, arises from the atmospheric pathway (Fig. 3; Tables 1-3). Notably, regarding the Northern Hemisphere jet shift, the atmospheric pathway dominates over the surface pathway (Figs. 1d and 3). This is likely the result of strong changes in longwave surface cloud-radiative heating in the northern high latitudes, and weak changes in shortwave surface cloud-radiative heating compared to the southern high latitudes (see Fig. 2). In summary, this demonstrates that in the MPI-ESM model considered here, the atmospheric pathway is as important as the surface 


\section{Southern Hemisphere Northern Hemisphere}

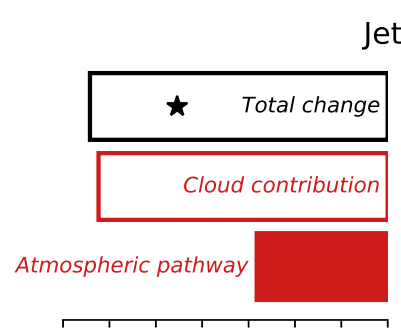

3
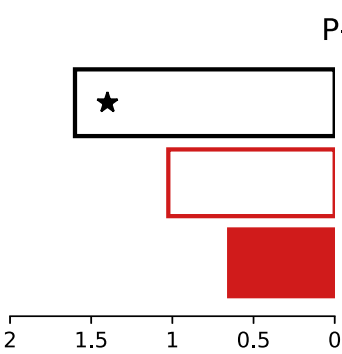

1.5

Hadley cell edge
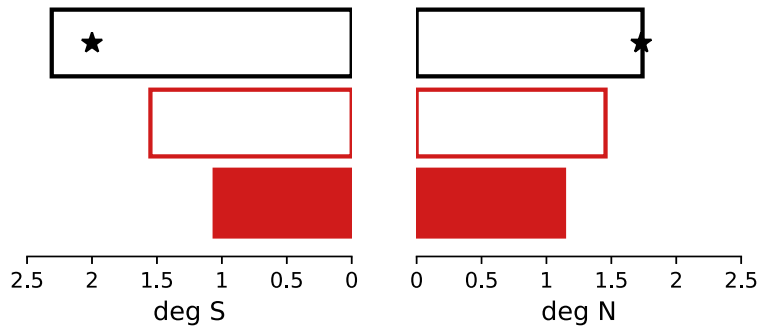

FIG. 3. Metrics of the poleward circulation expansion for the (left) Southern Hemisphere and (right) Northern Hemisphere in the MPI-ESM simulations SLAB and SSTSLAB. The black bar denotes the total change in response to quadrupled $\mathrm{CO}_{2}$, with the black star showing the values obtained in the SSTSLAB simulations. The open red bar shows the total cloud contribution in the SLAB simulations with interactive SST, and the filled red bar the cloud contribution due to the atmospheric pathway derived from the SSTSLAB simulations with prescribed SST.

pathway. The cloud-radiative impact thus cannot be understood from changes in surface cloud-radiative heating alone; it does include a strong contribution from changes in atmospheric cloud-radiative heating.

Figure 4 shows the cloud contribution to the temperature and zonal wind response via the atmospheric pathway in the SSTSLAB simulations. Near the surface, the temperature response is small. Thus, although changes in lower-tropospheric cloud-radiative heating are substantial, their circulation impact is limited because SST is prescribed. In fact, the cloud-induced temperature response is most pronounced in the upper troposphere, with distinct peak warming in the tropics similar to the SLAB simulations (also see dashed lines in Fig. 1e). The warming is collocated with changes in the

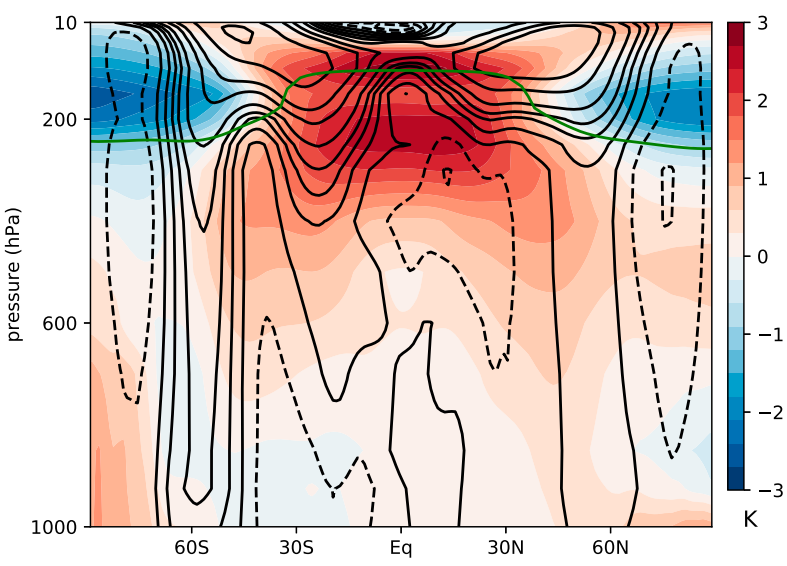

FIG. 4. The cloud contribution via the atmospheric pathway to the $4 \times \mathrm{CO}_{2}$ response of temperature (colors) and zonal wind (black contours). The cloud contribution is estimated by the SSTSLAB simulations with MPI-ESM. The green line depicts the present-day temperature tropopause. For the wind change, the same contour intervals as in Figs. $1 \mathrm{a}-\mathrm{c}$ are used: $1 \mathrm{~m} \mathrm{~s}^{-1}$ between 0 and $3.5 \mathrm{~m} \mathrm{~s}^{-1}$, $2 \mathrm{~m} \mathrm{~s}^{-1}$ between 5 and $10 \mathrm{~m} \mathrm{~s}^{-1}$, and $5 \mathrm{~m} \mathrm{~s}^{-1}$ for wind changes with a magnitude larger than $10 \mathrm{~m} \mathrm{~s}^{-1}$.

upper-tropospheric cloud-radiative heating. This shows that a substantial part of the total tropical uppertroposphere warming results from locally increased cloud-radiative heating, which acts in addition to increased latent heating and moist-adiabatic adjustment. Circulation theories and results from idealized models predict that preferentially warming the tropical upper-troposphere leads to a poleward expansion of the circulation via an increased upper-tropospheric equator-to-pole temperature gradient (Butler et al. 2010; Lorenz and DeWeaver 2007; Voigt and Shaw 2016; Yuval and Kaspi 2016). Although simulations with regional cloud changes would be needed to fully disentangle the role of lower- and upper-tropospheric cloud-radiative heating (Voigt and Shaw 2016), our analysis indicates that the changes in upper-troposphere cloud-radiative heating are central to the atmospheric pathway and the circulation expansion. The following sections will study model robustness and differences in the atmospheric pathway, with a focus on the upper troposphere and high-level clouds.

\section{The atmospheric pathway in the three models MPI-ESM, IPSL-CM5A, and ICON}

We now compare the atmospheric pathway in the three models MPI-ESM, IPSL-CM5A, and ICON. To this end, we perform simulations with SST and sea ice prescribed to the climatological values of the CMIP5 AMIP protocol (average over years 1979-2008; Taylor et al. 2012). Global warming is mimicked by a uniform SST increase by $4 \mathrm{~K}$, 
consistent with the CMIP5 AMIP4K simulations. As before, we use the cloud-locking method to decompose the circulation response. We refer to these simulations as SST4K. The model comparison allows us to study model robustness and differences in the atmospheric pathway of the cloud-radiative impact.

MPI-ESM is used in the same setup as in section 3, apart from the fact that SST and sea ice are now prescribed to the AMIP instead of the SLAB climatology. For IPSLCM5A, we use the atmospheric component LMDz5A (svn revision 1707; Dufresne et al. 2013) in a low resolution of $3.75^{\circ}$ longitude $\times 1.875^{\circ}$ latitude and 39 levels. For ICON we use the atmospheric component of the ICON model version 2.1.00 with the physics package developed for numerical weather prediction (Zängl et al. 2015) in horizontal resolution R2B04 $(160 \mathrm{~km})$ and 47 levels. The setup for IPSL-CM5A and ICON is the same as that for MPI-ESM, with the following small differences. For IPSLCM5A, ozone is set to values from year 1995, and aerosol is set to preindustrial values. For ICON, we use year 2012 values for well-mixed greenhouse gases $\left(\mathrm{CO}_{2}=390\right.$ ppmv, $\mathrm{CH}_{4}=1800$ ppbv, $\mathrm{N}_{2} \mathrm{O}=322$ ppmv, $\mathrm{CFC}_{11}=240$ pptv, and $\mathrm{CFC}_{12}=532 \mathrm{pptv}$ ), ozone is set to the Global and Regional Earth-system (Atmosphere) Monitoring Using Satellite and in-situ Data (GEMS) climatology from the ECMWF IFS numerical weather prediction model, and aerosol from Tegen et al. (1997) is used. We have verified that the annual-mean zonal-mean circulation of our MPI-ESM and IPSL-CM5A setups is in close agreement with the CMIP5 AMIP simulations archived at the Earth System Grid Federation.

Before comparing the three models, we analyze to what extent the atmospheric pathway depends on the pattern of SST increase. To this end, we compare the SST4K and SSTSLAB simulations with MPI-ESM. SST is increased uniformly in the former, and with a pattern in the latter. The response of zonal wind and atmospheric temperature and the change in atmospheric cloud-radiative heating in the SST4K simulations are illustrated in Figs. 5a, 5d, and 5g. As for the SSTSLAB simulations, the atmospheric pathway of the cloudradiative impact contributes about half to the total zonal wind response (cf. Figs. 5a and 1d) as well as the total poleward circulation expansion estimated from the circulation metrics (Tables 1-3). Changes in atmospheric cloud-radiative heating are weaker in SST4K due to less surface warming, but have the same spatial pattern as in the SSTSLAB $\operatorname{setup}^{2}$ (Figs. $5 \mathrm{~g}$ and $2 \mathrm{~b}$ ).

\footnotetext{
${ }^{2}$ By virtue of the simulation design the changes of atmospheric cloud-radiative heating in the SSTSLAB setup are the same as in the SLAB setup, which are shown in Fig. 2.
}

Figure 6 confirms the visual comparison by plotting the difference in changes of atmospheric cloud-radiative heating between the two setups, with the SST4K changes scaled by the ratio of global-mean surface warming between SSTSLAB and SST4K $(7.7 \mathrm{~K} / 4.3 \mathrm{~K})$ to take into account the larger warming in SSTSLAB. The differences are mostly small, apart from near the surface and a vertical offset in the upper troposphere due to a larger upward expansion of the troposphere in SSTSLAB. This shows that changes in atmospheric cloud-radiative heating scale approximately with the magnitude of global-mean warming, consistent with a larger circulation response to cloud changes in SSTSLAB compared to SST4K (Tables 1-3). ${ }^{3}$ Moreover, the pattern of the response of atmospheric temperature and zonal wind in SST4K is very similar to that in SSTSLAB, with peak warming in the tropical and midlatitude upper troposphere, and a muted temperature response in the boundary layer. Because changes in atmospheric cloud-radiative heating and their circulation impact do not strongly depend on the pattern of the SST increase, the atmospheric pathway can be meaningfully compared between models through simulations with uniform 4-K SST increase.

We now compare the atmospheric pathway between the three models in the SST4K simulations. In all three models, cloud-radiative changes amplify the poleward expansion of the circulation. This is evident from their contribution to changes in the near-surface zonal wind (Figs. 5a-c) as well as the circulation metrics, which all signal a poleward expansion (Tables 1-3). However, the magnitude of the cloud-radiative impact differs strongly between models. Most notably, IPSL-CM5A shows a 3 times larger cloud-radiative impact on near-surface zonal wind and the position of the extratropical jet streams than MPI-ESM. IPSL-CM5A also shows a much larger cloudradiative impact on the Hadley cell edge, and on the latitude of net precipitation in the Southern Hemisphere.

The large model differences in the magnitude of the atmospheric pathway are related to large model differences in the response of atmospheric temperatures (Figs. 5d-f) and changes of atmospheric cloud-radiative heating (Figs. 5g-i). Model differences in changes of atmospheric cloud-radiative heating are large in the lower as well as in the upper troposphere. In both regions, IPSL-CM5A stands out as the model with the strongest changes. Changes in lower-tropospheric cloud-radiative heating differ between models even

\footnotetext{
${ }^{3}$ The total circulation response in SST4K and SSTSLAB does not scale with the global-mean warming, indicating that changes in SST pattern are important (Grise and Polvani 2016).
} 
MPI-ESM

IPSL-CM5A

ICON
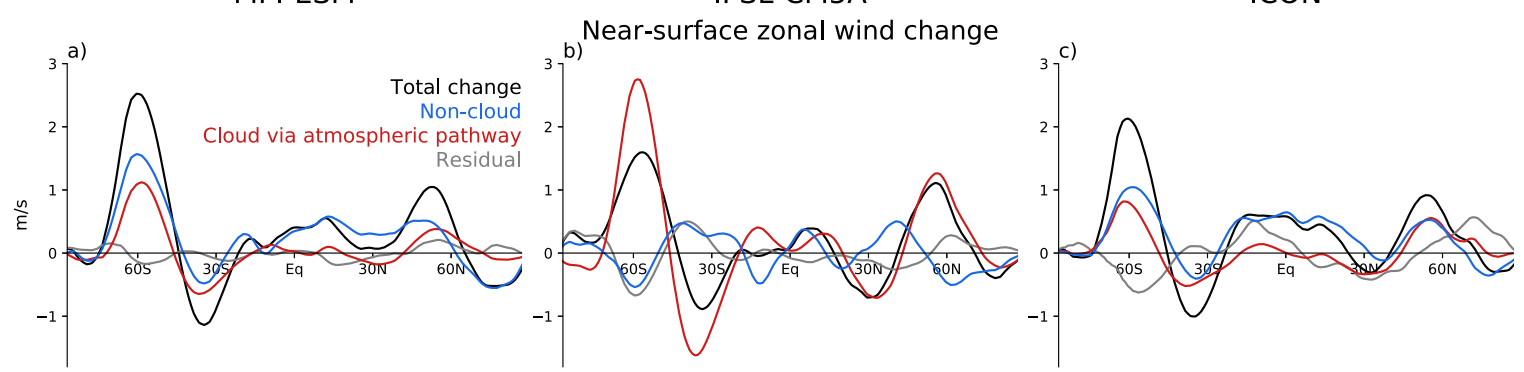

Cloud impact on temperature and zonal wind from atmospheric pathway
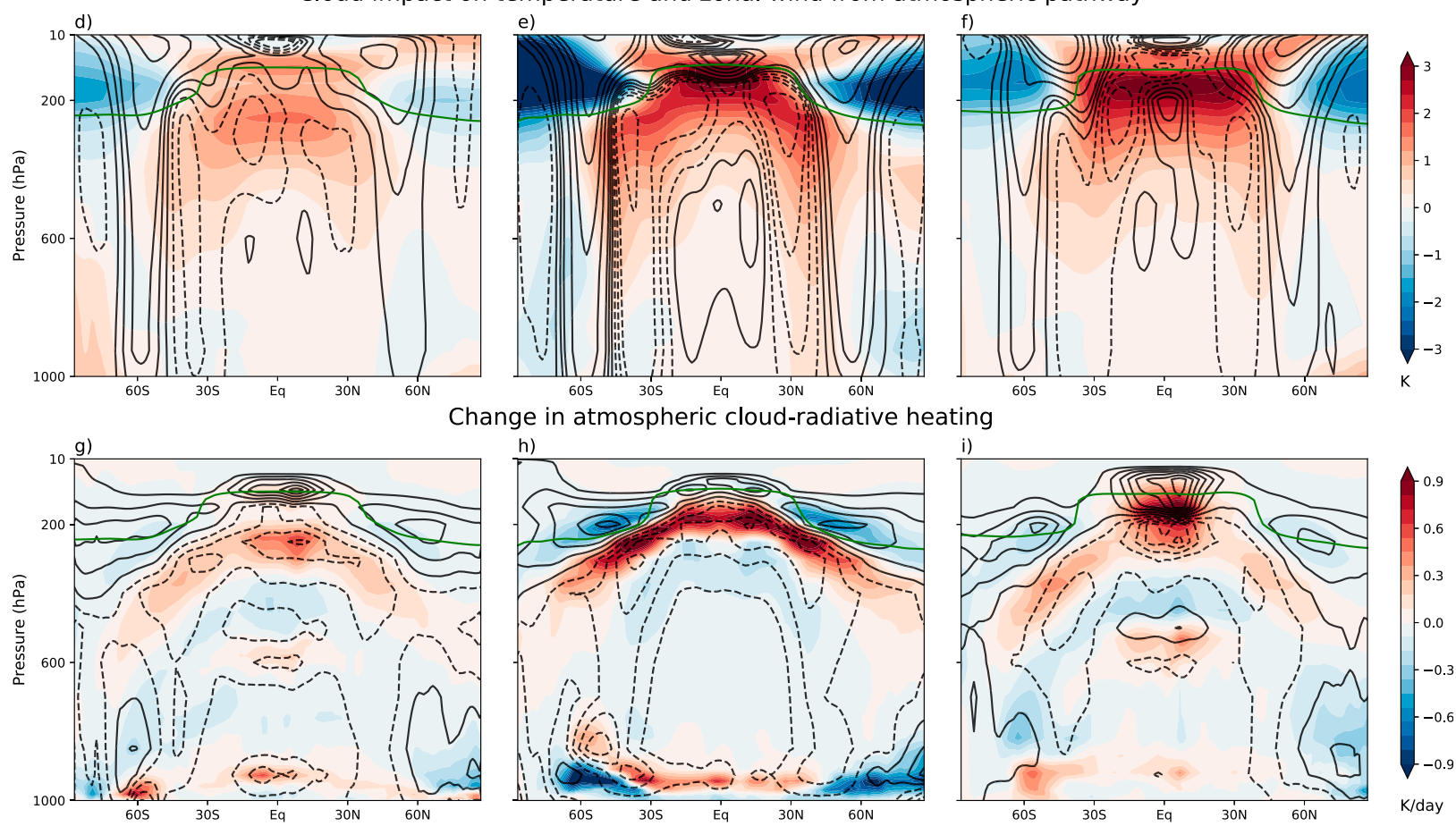

FIG. 5. Model comparison of the atmospheric pathway in response to a uniform 4-K SST increase in (left) MPI-ESM, (center) IPSLCM5A, and (right) ICON. (a)-(c) Change in near-surface zonal wind at $850 \mathrm{hPa}$. (d)-(f) Cloud impact on temperature (colors) and zonal wind (black contour lines; solid contours indicate westerlies, dashed contours indicate easterlies). To highlight the wind response in the lower and midtroposphere, nonequal contour intervals are used: $0.4 \mathrm{~m} \mathrm{~s}^{-1}$ between 0 and $1 \mathrm{~m} \mathrm{~s}^{-1}, 1 \mathrm{~m} \mathrm{~s}^{-1}$ between 1 and $5 \mathrm{~m} \mathrm{~s}{ }^{-1}$, and $5 \mathrm{~m} \mathrm{~s}^{-1}$ for wind changes with a magnitude larger than $5 \mathrm{~m} \mathrm{~s}^{-1}$. The green line depicts the present-day temperature tropopause. (g)-(i) Changes in atmospheric cloud-radiative heating in colors and cloud fraction in black contour lines (contour interval of $2 \%$; dashed contours correspond to a negative change and solid contours to a positive change).

in a qualitative sense (e.g., in the high latitudes), but their circulation impact is limited because SST is prescribed and changes in lower-tropospheric temperature are small. In contrast, in the upper troposphere the models simulate the same qualitative pattern of warming and changes in cloud-radiative heating, with an arc of anomalous heating in the tropics and midlatitudes. As before, this points to the importance of changes in upper-tropospheric cloud-radiative heating and highlevel clouds. The upper-tropospheric cloud response follows the fixed-anvil temperature hypothesis (Hartmann and Larson 2002; Thompson et al. 2017). Vertical profiles of tropical and midlatitude cloud fraction and cloud ice have a similar shape in the global-warming simulation as in the present-day simulation (Fig. 7), signaling an upward cloud shift. The same pattern of changes in upper-tropospheric cloud-radiative heating was found in the SLAB simulations of section 3, the aquaplanet simulations of Voigt and Shaw (2016), and the COOKIE analysis of Li et al. (2019), supporting that this is a qualitatively robust model response tied to the rise of the tropopause and high-level clouds.

While changes in upper-tropospheric cloud-radiative heating are qualitatively robust, their magnitude differs by more than a factor of 3 between the models. Near the equator the cloud-radiative heating changes 


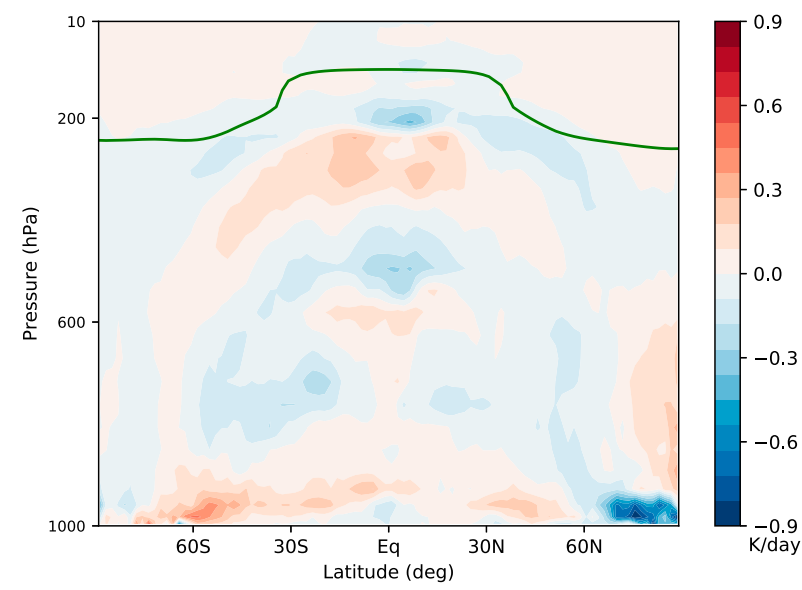

FIG. 6. Difference in the change of atmospheric cloud-radiative heating in the MPI-ESM model between the SST4K and SSTSLAB setups. The SST4K value is rescaled by the ratio of global-mean surface temperature changes in the two setups ( 4.3 vs $7.7 \mathrm{~K}$ ).

are strongest in ICON. In the midlatitudes, where radiative heating is particularly effective in shifting the circulation poleward (Voigt and Shaw 2016; Shaw and Tan 2018), the cloud-radiative heating changes are strongest in IPSL-CM5A. MPI-ESM shows the weakest cloud-radiative heating changes, and midlatitude cloudradiative heating changes comparable to ICON. Although the circulation impact of cloud-radiative heating changes might depend on their exact location (Butler et al. 2010; Lu et al. 2014) and are shaped by convection and latent heat release (Voigt and Shaw 2016), the model differences in the magnitude of the atmospheric pathway are clearly linked to model differences in cloud-radiative heating changes, consistent with dry models forced by heating from cloud-radiative changes (Voigt and Shaw 2016; Li et al. 2019). In particular, the much stronger circulation response in IPSL-CM5A compared to MPIESM and ICON is linked to much stronger anomalous cloud-radiative heating in the upper troposphere.

In summary, we have shown that 1) the atmospheric pathway is important in three models, and 2) its magnitude is strongly model dependent due to strong differences in changes of atmospheric cloud-radiative heating, in particular in the upper troposphere. In the following section we will study why the models differ so markedly in changes of upper-tropospheric cloud-radiative heating.

\section{Reasons for model differences in changes of upper-tropospheric cloud-radiative heating and comparison to observations}

We now study the reasons for model differences in changes of upper-tropospheric cloud-radiative heating. Specifically, we test to what extent the model differences result from the present-day climate. This is motivated by the recent work of Li et al. (2019) and the idea that the upward shift of high-level clouds could translate model differences in cloud-radiative heating in the present-day climate to model differences in changes of cloudradiative heating under global warming.

The upper panels of Fig. 8 compare vertical profiles of tropical-mean and midlatitude-mean changes of cloudradiative heating under global warming in the three models. The lower panels of Fig. 8 compare the cloudradiative heating in the present-day climate, calculated as the difference in the radiative heating rate for an atmosphere with and without clouds. Several characteristic features of the models' changes in cloud-radiative heating under global warming appear to be linked to the present-day cloud-radiative heating. IPSL-CM5A has the strongest changes in heating and the strongest present-day heating. For MPI-ESM, the two maxima in heating changes in the tropical upper-troposphere are also seen in the present-day heating. The model differences in the present-day heating are related to model differences in present-day cloud fraction and cloud ice (Fig. 7), as well as to model differences in the radiative treatment of clouds.

The link between the cloud-radiative heating in the present-day climate and changes in cloud-radiative heating under global warming is rooted in the models' robust rise of high-level tropical and midlatitude clouds. This suggests that a substantial part of the changes in upper-tropospheric cloud-radiative heating can be captured by an upward shift of the present-day cloudradiative heating. To test this idea, we apply the vertical shift framework of Singh and O'Gorman (2012). We assume that cloud-radiative heating shifts upward in accordance with relative humidity, which we consider a proxy for cloud fraction; this is consistent with the upward shift of radiative heating derived in Singh and O'Gorman (2012) [their Eq. (12)]. Another approach is to shift the present-day cloud-radiative heating upward so that it remains at the same temperature. This approach was taken by Li et al. (2019) for IPSL-CM5A and is more closely linked to the fixed anvil temperature hypothesis, but requires the models' global warming response as input. In contrast, our approach is solely based on the present-day climate.

The upward-shifted version of the present-day cloudradiative heating at pressure $p$ is given as the presentday value at pressure $\beta p$. We use $\beta=1$.2. The value is derived from Eq. (15) of Singh and O'Gorman (2012) assuming a $5-\mathrm{K}$ warming at the top of the boundary layer, which is a typical value in the SST4K simulations. The predicted changes of cloud-radiative heating are defined as the difference in the upward-shifted and the 


\section{Tropics}

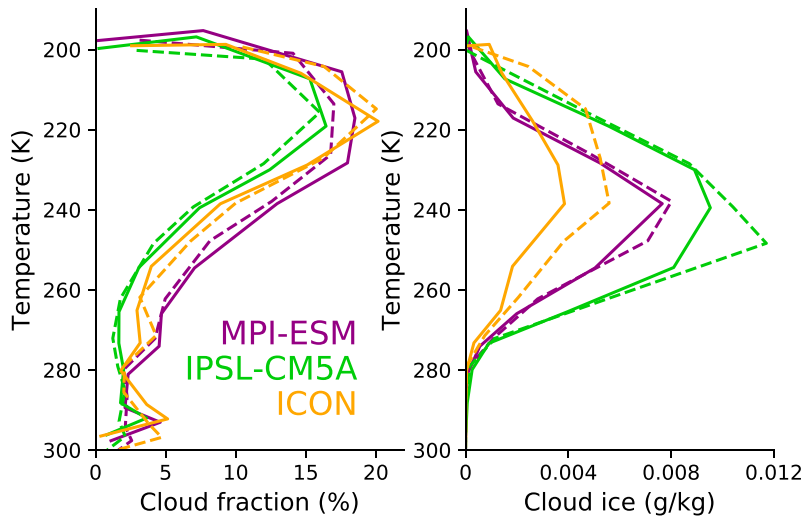

Midlatitudes

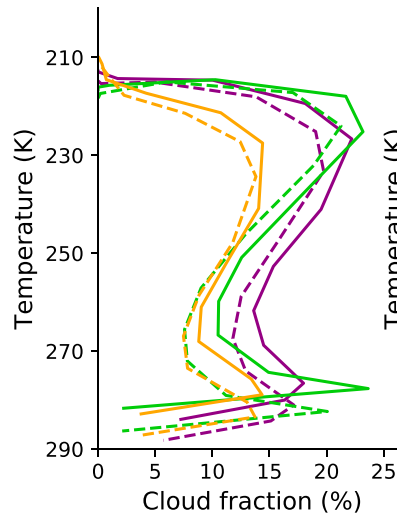

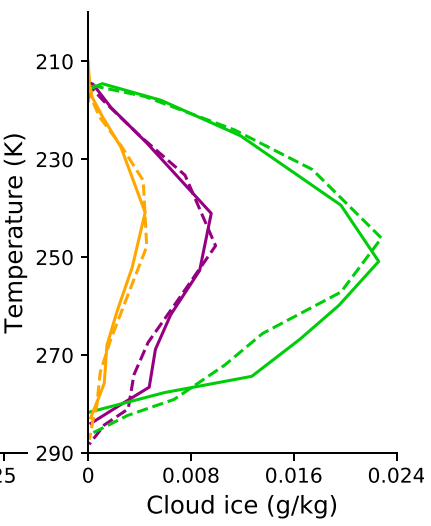

FIG. 7. Vertical profiles of cloud fraction and cloud ice as a function of atmospheric temperature in the SST4K simulations with presentday SST (solid) and with SST increased by $4 \mathrm{~K}$ (dashed). (a) The tropics (average between $30^{\circ} \mathrm{N}$ and $30^{\circ} \mathrm{S}$ ) and (b) the midlatitudes (average over $30^{\circ}-60^{\circ} \mathrm{N}$ and $30^{\circ}-60^{\circ} \mathrm{S}$ ).

present-day cloud-radiative heating, and are shown by the thin dashed lines in Figs. 8a and 8b.

In the midlatitudes, changes of cloud-radiative heating are well approximated by the upward shift of the present-day cloud-radiative heating. In the tropics, the approximation works well for IPSL-CM5A and, to a somewhat smaller extent, for MPI-ESM. It fails to capture the changes of cloud-radiative heating in ICON because of a strong increase in cloud ice (Fig. 7). Overall, however, while changes in cloud fraction and cloud hydrometeors can contribute (e.g., in the tropics in ICON), the analysis highlights that model differences in the present-day upper-tropospheric cloud-radiative heating are a large contributor to model differences in changes of upper-tropospheric cloud-radiative heating under global warming.

Given the link between the changes of cloud-radiative heating under global warming and the cloud-radiative heating in the present-day climate, we assess the models' ability to represent the radiative heating of high-level clouds in the present-day climate. To this end we use satellite-based observations of the present-day cloudradiative heating provided by CloudSat/CALIPSO for years 2007-10 (Haynes et al. 2013), which combine retrievals from the CloudSat Cloud Profiling Radar and the CALIPSO lidar. We use all-sky and clear-sky radiative fluxes from the 2B-FLXHR-lidar product version P2R04 (Henderson et al. 2013) and the ECMWF-AUX ancillary data, version P_R04, which provides atmospheric pressure for the vertical levels of each CloudSat/ CALIPSO profile. Following previous work ( $\mathrm{Li}$ et al. 2014), we bin the vertical CloudSat/CALIPSO profiles into a $2.5^{\circ} \times 2.5^{\circ}$ latitude-longitude grid and for $240-\mathrm{m}$ altitude intervals. The CloudSat/CALIPSO observations are included in Figs. $8 \mathrm{c}$ and $8 \mathrm{~d}$.
In all models, the cloud-radiative heating deviates from observations, but to a degree that depends on the model and region. The deviations are particularly striking for IPSL-CM5A, for which the cloud-radiative heating is up to 4 times stronger compared to the observations in both the tropics and the midlatitudes. This suggests that in IPSL-CM5A, changes of uppertropospheric cloud-radiative heating and the atmospheric pathway are too strong. For MPI-ESM and ICON, in which the atmospheric pathway is weaker but still important, the deviations between simulated and observed cloud-radiative heating are smaller. In the midlatitudes, the two models compare relatively well to observations. In the tropics, the deviations are substantial but not as severe as in IPSL-CM5A. For MPIESM the tropical cloud-radiative heating magnitude is comparable to observations, and the vertical profile is at least somewhat similar. Overall, the analysis suggests that IPSL-CM5A overestimates the atmospheric pathway of the cloud-radiative impact, and demonstrates the need for model improvements regarding the radiative heating by high-level clouds.

Finally, we analyze the cloud-radiative heating from ERA-Interim reanalysis for the years 2007-10. ERAInterim constrains a numerical weather prediction model by observations of the large-scale atmospheric state, which one could hope leads to a more accurate cloud-radiative heating. This is not the case, however. The ERA-Interim reanalysis differs as strongly from the observations as the climate models. This implies that using higher resolution and constraining the large-scale atmospheric state are not sufficient to simulate a realistic cloud-radiative heating, and that model assumptions regarding cloud microphysics and the optical properties of ice clouds play a key role (Wendisch et al. 


\section{Tropics}

Midlatitudes

\section{Changes in cloud-radiative heating under global warming}

a)

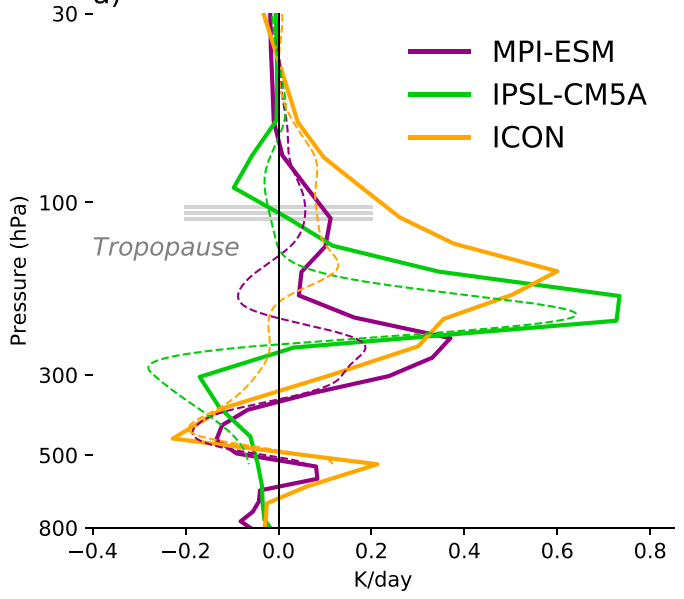

b)

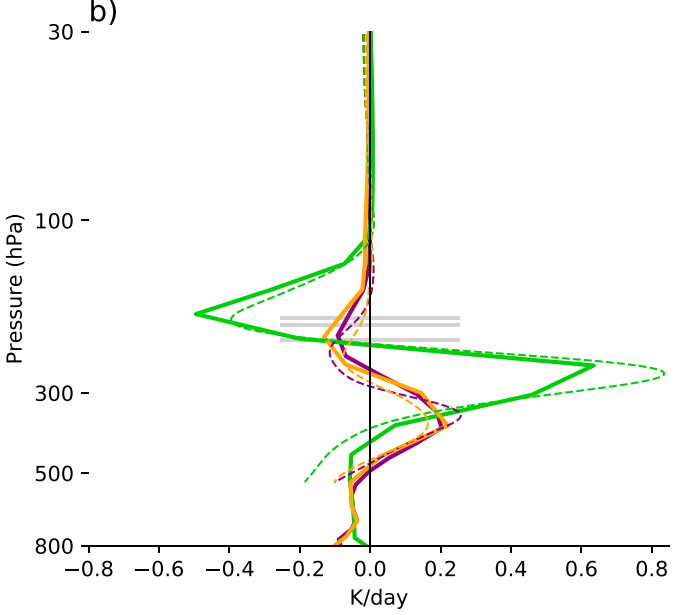

Cloud-radiative heating in present-day climate
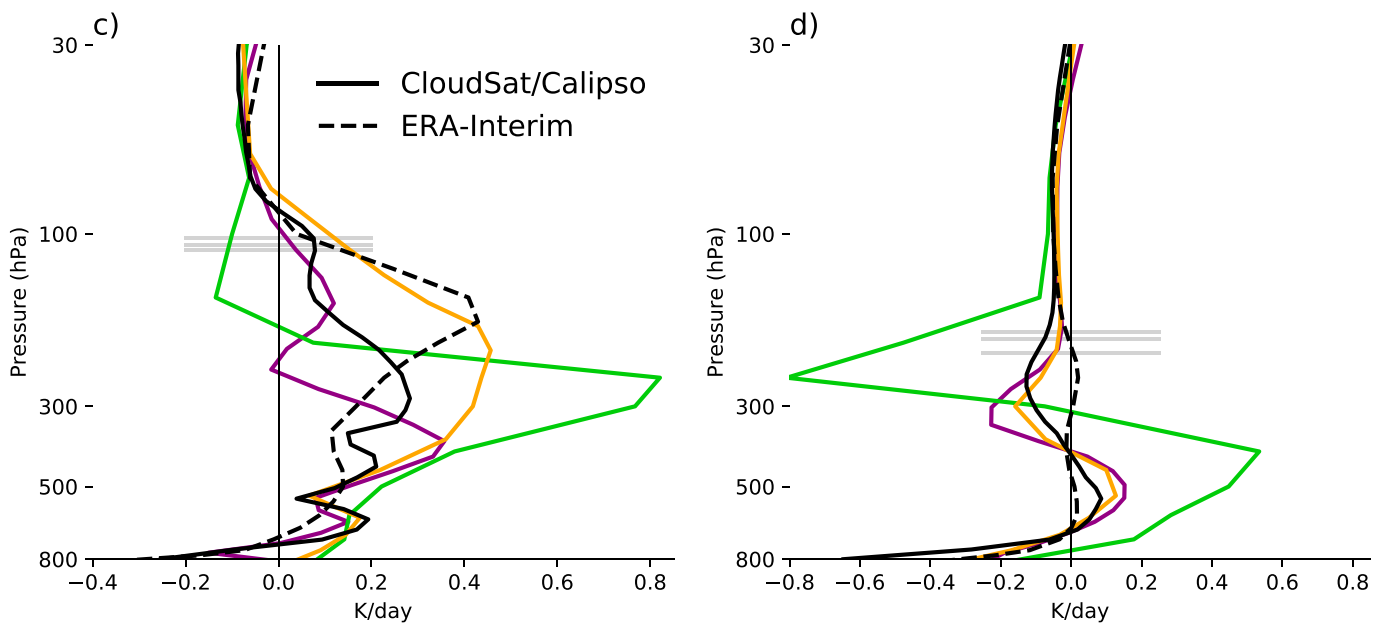

FIG. 8. (top) Vertical profile of changes in atmospheric cloud-radiative heating in the SST4K simulation with uniform 4-K SST increase, for (a) the tropics (average between $30^{\circ} \mathrm{N}$ and $30^{\circ} \mathrm{S}$ ) and (b) the midlatitudes (average over $30^{\circ}-60^{\circ} \mathrm{N}$ and $30^{\circ}-60^{\circ} \mathrm{S}$ ). The dashed lines show the cloud-radiative heating changes predicted by the upward shift of the present-day climatology in (c) and (d) (see section 5 for details). This illustrates that much of the model differences in changes of cloud-radiative heating result from model differences in the present-day clouds. (bottom) The cloud-radiative heating in the present-day climate, defined as all-sky minus clear-sky radiative heating, in (c) the tropics and (d) the midlatitudes. The black lines show the present-day cloud-radiative heating from CloudSat/CALIPSO observations and ERA-Interim forecasts.

2007). Although the CloudSat/CALIPSO observations themselves are affected by uncertainties (Hong et al. 2016), the comparison with global climate models and the reanalysis demonstrates the shortcomings of current models to adequately represent high-level clouds and their radiative interaction. The model differences in cloud ice and cloud-radiative heating reported here are typical for global climate models used to project the response of the atmospheric circulation to global warming ( $\mathrm{Li}$ et al. 2016). This calls for improvements in the processes that govern high-level clouds, in particular those related to cloud ice.

\section{Conclusions}

Cloud-radiative interactions and their associated radiative feedbacks are among the largest sources of uncertainties in projections of future climate change (Bony et al. 2015). Recent work has demonstrated that cloud-radiative interactions not only govern model 
uncertainties in the magnitude of global-mean surface warming and climate sensitivity, but also play an important role for the circulation response, including the poleward expansion of the circulation. The cloudradiative impact can be separated into a surface pathway, which operates via radiative perturbations of the surface energy balance, and an atmospheric pathway, which operates via radiative perturbations of the atmosphere energy balance in the absence of surface temperature changes. This paper is the first to quantify the relative roles of the atmospheric and surface pathways. It is also the first to compare the atmospheric pathway in three global models run with realistic Earth boundary conditions that include continents using the cloud-locking method. Previously, this was done only in aquaplanet simulations (Voigt and Shaw 2015, 2016).

We show that, at least in the MPI-ESM model used here, the atmospheric pathway is as important as the surface pathway in amplifying the poleward circulation expansion in response to global warming. Thus, the circulation response is shaped both by changes in surface cloud-radiative heating from low-level clouds (Ceppi and Shepherd 2017) and changes in atmospheric cloudradiative heating from high-level clouds (Voigt and Shaw 2015, 2016; Li et al. 2019).

By comparing three models we show that the atmospheric pathway is a qualitatively robust model feature, but that its magnitude differs strongly between models. This was suggested by the COOKIE analysis of Li et al. (2019); here we explicitly demonstrate this by means of the cloud-locking method. The differences are tied to strong model differences in changes of the atmospheric cloud-radiative heating, in particular in the upper troposphere. Simulations with regionally locked clouds (Voigt and Shaw 2016) would be needed to fully separate the role of lower- and upper-tropospheric changes for the atmospheric pathway. However, the changes in lower-tropospheric cloud-radiative heating are less consistent between models, and they are less efficient in affecting the circulation because SST is prescribed. This has led us to focus our analysis on the changes of uppertropospheric cloud-radiative heating and high-level clouds.

We find that a prominent feature of the changes in upper-tropospheric cloud-radiative heating is an arc of heating below the tropopause. This heating pattern was previously found in the aquaplanet work of Voigt and Shaw (2016). Changes of upper-tropospheric cloudradiative heating do not strongly depend on the surface conditions and the pattern of surface warming and thus can be fruitfully studied in a hierarchy of model setups. In this sense, the current paper completes the hierarchical work on the circulation impact of high-level clouds via the atmospheric pathway started in Voigt and Shaw (2016) and recently also considered by Li et al. (2019): the poleward circulation expansion in response to changes of upper-tropospheric cloud-radiative heating from high-level cloud changes has emerged as a robust and important feature of dry Held-Suarez models, aquaplanet models, and models run with present-day boundary conditions. We note that high-level clouds might also impact the circulation via the surface pathway, such as via reduced cloud fraction and surface shortwave cloud-radiative heating (Mauritsen et al. 2013; Bony et al. 2016). Studying such possible effects would require simulations with interactive SST and isolated high-level cloud changes, and is left for future work.

We find that much of the change in upper-tropospheric cloud-radiative heating and model differences therein results from the upward shift of tropical and midlatitude high-level clouds and their radiative heating in the present-day climate. This shows that high-level clouds are important not only for the present-day circulation (Li et al. 2015; Harrop and Hartmann 2016; Watt-Meyer and Frierson 2017; Albern et al. 2018), but also for the circulation response to global warming. The upward shift of high-level clouds with increasing surface temperature is a robust signal in models, is in line with thermodynamic and radiative constraints on the temperature of high-level cloud tops (Hartmann and Larson 2002; Thompson et al. 2017), and is an emergent signal of observed climate change (Norris et al. 2016). The upward shift leads to radiative heating below the tropopause that is qualitatively robust across models but varies greatly in magnitude. It is somewhat sobering to see that all three models used here show substantial deviations from observed cloud-radiative heating, in particular in the tropics. At the same time this illustrates large potential for progress. To help realize this potential, model intercomparison studies should provide diagnostics of the vertical structure of atmospheric cloud-radiative heating (Webb et al. 2017) and, if possible, diagnostics of changes in the atmospheric cloud-radiative heating in response to global warming.

Our modeling work and comparison with observed cloud-radiative heating highlights the need for advancing understanding of high-level clouds, their radiative interactions, and their coupling to the large-scale circulation. Our findings indicate that the circulation impact of highlevel cloud changes via the atmospheric pathway scales with the magnitude of global-mean surface warming and depends on the atmospheric cloud-radiative heating in the present-day climate. This suggest that assuming the magnitude of global-mean surface warming is known, the 
circulation impact of high-level clouds via the atmospheric pathway can be constrained by combining global climate models and observations. This could contribute to more reliable predictions of regional climate change.

Acknowledgments. AV, NA, and GP were supported by the German Ministry of Education and Research (BMBF) and FONA: Research for Sustainable Development (https://www.fona.de) under Grant Agreement 01LK1509A. This work is part of $\mathrm{HD}(\mathrm{CP})^{2}$ : High Definition Clouds and Precipitation for Advancing Climate Prediction. We thank Thomas Leisner, Robert Pincus, and Isla Simpson for discussions and comments on earlier drafts of the paper. The MPI-ESM model simulations were performed at the RCC of the University of Chicago. We thank Tiffany Shaw for providing us with computer resources at RCC. The ICON simulations were performed at the DKRZ in Hamburg, Germany. The IPSL-CM5A simulations were performed at a Linux cluster of the Lamont-Doherty Earth Observatory. The model output is archived at the bwDataArchive of KIT Steinbuch Computing Center in Karlsruhe, Germany, for MPI-ESM and IPSL-CM5A, and at DKRZ in Hamburg, Germany, for ICON. The climate model datasets generated and analyzed for the current study are available from the corresponding author on reasonable request. The CloudSat/ CALIPSO data were obtained from http://www. cloudsat.cira.colostate.edu. Ying $\mathrm{Li}$ is thanked for providing an insolation routine, which was helpful to compute shortwave heating rates from CloudSat/ CALIPSO. The ERA-Interim reanalysis data were obtained from the ECMWF Mars archive.

\section{REFERENCES}

Albern, N., A. Voigt, S. A. Buehler, and V. Grützun, 2018: Robust and nonrobust impacts of atmospheric cloud-radiative interactions on the tropical circulation and its response to surface warming. Geophys. Res. Lett., 45, 8577-8585, https:// doi.org/10.1029/2018GL079599.

Barnes, E. A., and L. M. Polvani, 2013: Response of the midlatitude jets, and of their variability, to increased greenhouse gases in CMIP5 models. J. Climate, 26, 7117-7135, https://doi.org/ 10.1175/JCLI-D-12-00536.1.

Bony, S., G. Bellon, D. Klocke, S. Sherwood, S. Fermepin, and S. Denvil, 2013: Robust direct effect of carbon dioxide on tropical circulation and regional precipitation. Nat. Geosci., 6 , 447-451, https://doi.org/10.1038/ngeo1799.

_- and Coauthors, 2015: Clouds, circulation and climate sensitivity. Nat. Geosci., 8, 261-268, https://doi.org/10.1038/ ngeo2398.

, B. Stevens, D. Coppin, T. Becker, K. A. Reed, A. Voigt, and B. Medeiros, 2016: Thermodynamic control of anvil-cloud amount. Proc. Natl. Acad. Sci. USA, 113, 8927-8932, https:// doi.org/10.1073/pnas.1601472113.
Butler, A. H., D. W. J. Thompson, and R. Heikes, 2010: The steadystate atmospheric circulation response to climate change-like thermal forcings in a simple general circulation model. J. Climate, 23, 3474-3496, https://doi.org/10.1175/2010JCLI3228.1.

Ceppi, P., and D. L. Hartmann, 2016: Clouds and the atmospheric circulation response to warming. J. Climate, 29, 783-799, https://doi.org/10.1175/JCLI-D-15-0394.1.

, and T. G. Shepherd, 2017: Contributions of climate feedbacks to changes in atmospheric circulation. J. Climate, 30, 90979118, https://doi.org/10.1175/JCLI-D-17-0189.1.

, M. D. Zelinka, and D. L. Hartmann, 2014: The response of the Southern Hemispheric eddy-driven jet to future changes in shortwave radiation in CMIP5. Geophys. Res. Lett., 41, 3244 3250, https://doi.org/10.1002/2014GL060043.

, F. Brient, M. D. Zelinka, and D. L. Hartmann, 2017: Cloud feedback mechanisms and their representation in global climate models. Wiley Interdiscip. Rev.: Climate Change, 8, e465, https://doi.org/10.1002/wcc.465.

Chen, G., and I. M. Held, 2007: Phase speed spectra and the recent poleward shift of Southern Hemisphere surface westerlies. Geophys. Res. Lett., 34, L21805, https://doi.org/10.1029/ 2007GL031200.

Collins, M., and Coauthors, 2018: Challenges and opportunities for improved understanding of regional climate dynamics. Nat. Climate Change, 8, 101-108, https://doi.org/10.1038/s41558017-0059-8.

Colman, R. A., and B. J. McAvaney, 1997: A study of general circulation model climate feedbacks determined from perturbed sea surface temperature experiments. J. Geophys. Res., 102, 19383-19402, https://doi.org/10.1029/97JD00206.

Deser, C., and A. S. Phillips, 2009: Atmospheric circulation trends, 1950-2000: The relative roles of sea surface temperature forcing and direct atmospheric radiative forcing. J. Climate, 22, 396-413, https://doi.org/10.1175/2008JCLI2453.1.

Dufresne, J.-L., and Coauthors, 2013: Climate change projections using the IPSL-CM5 Earth system model: From CMIP3 to CMIP5. Climate Dyn., 40, 2123-2165, https://doi.org/10.1007/ s00382-012-1636-1.

Giorgetta, M. A., and Coauthors, 2013: Climate and carbon cycle changes from 1850 to 2100 in MPI-ESM simulations for the Coupled Model Intercomparison Project phase 5. J. $A d v$. Model. Earth Syst., 5, 572-597, https://doi.org/10.1002/ jame.20038.

Grise, K. M., and L. M. Polvani, 2016: Is climate sensitivity related to dynamical sensitivity? J. Geophys. Res. Atmos., 121, 51595176, https://doi.org/10.1002/2015JD024687.

Harrop, B. E., and D. L. Hartmann, 2016: The role of cloud radiative heating in determining the location of the ITCZ in aquaplanet simulations. J. Climate, 29, 2741-2763, https:// doi.org/10.1175/JCLI-D-15-0521.1.

Hartmann, D. L., and K. Larson, 2002: An important constraint on tropical cloud-climate feedback. Geophys. Res. Lett., 29, 1951, https://doi.org/10.1029/2002GL015835.

Haynes, J. M., T. H. Vonder Haar, T. L'Ecuyer, and D. Henderson, 2013: Radiative heating characteristics of Earth's cloudy atmosphere from vertically resolved active sensors. Geophys. Res. Lett., 40, 624-630, https://doi.org/10.1002/grl.50145.

Henderson, D. S., T. L'Ecuyer, G. Stephens, P. Partain, and M. Sekiguchi, 2013: A multisensor perspective on the radiative impacts of clouds and aerosols. J. Appl. Meteor. Climatol., 52, 853-871, https://doi.org/10.1175/JAMC-D-12-025.1.

Hong, Y., G. Liu, and J.-L. F. Li, 2016: Assessing the radiative effects of global ice clouds based on CloudSat and CALIPSO 
measurements. J. Climate, 29, 7651-7674, https://doi.org/ 10.1175/JCLI-D-15-0799.1.

Kidston, J., G. K. Vallis, S. M. Dean, and J. A. Renwick, 2011: Can the increase in the eddy length scale under global warming cause the poleward shift of the jet streams? J. Climate, 24, 3764-3780, https://doi.org/10.1175/2010JCLI3738.1.

Kinne, S., and Coauthors, 2013: MAC-v1: A new global aerosol climatology for climate studies. J. Adv. Model. Earth Syst., 5, 704-740, https://doi.org/10.1002/jame.20035.

Li, J.-L. F., D. E. Waliser, G. Stephens, and S. Lee, 2016: Characterizing and understanding cloud ice and radiation budget biases in global climate models and reanalysis. Multiscale Convection-Coupled Systems in the Tropics: A Tribute to Dr. Michio Yanai, Meteor Monogr., No. 56, 13.1-13.20, https:// doi.org/10.1175/AMSMONOGRAPHS-D-15-0007.1.

Li, Y., D. W. J. Thompson, Y. Huang, and M. Zhang, 2014: Observed linkages between the northern annular mode/North Atlantic Oscillation, cloud incidence, and cloud radiative forcing. Geophys. Res. Lett., 41, 1681-1688, https://doi.org/ 10.1002/2013GL059113.

,-- , and S. Bony, 2015: The influence of atmospheric cloud radiative effects on the large-scale atmospheric circulation. J. Climate, 28, 7263-7278, https://doi.org/10.1175/JCLI-D-1400825.1 .

,,,--- and T. M. Merlis, 2019: Thermodynamic control on the poleward shift of the extratropical jet in climate change simulations: The role of rising high clouds and their radiative effects. J. Climate, 32, 917-934, https://doi.org/10.1175/JCLID-18-0417.1.

Lorenz, D. J., and E. T. DeWeaver, 2007: Tropopause height and zonal wind response to global warming in the IPCC scenario integrations. J. Geophys. Res., 112, D10119, https://doi.org/ 10.1029/2006JD008087.

Lu, J., G. A. Vecchi, and T. Reichler, 2007: Expansion of the Hadley cell under global warming. Geophys. Res. Lett., 34, L06805, https://doi.org/10.1029/2006GL028443.

— L. Sun, Y. Wu, and G. Chen, 2014: The role of subtropical irreversible PV mixing in the zonal mean circulation response to global warming-like thermal forcing. J. Climate, 27, 22972316, https://doi.org/10.1175/JCLI-D-13-00372.1.

Mauritsen, T., R. G. Graversen, D. Klocke, P. L. Langen, B. Stevens, and L. Tomassini, 2013: Climate feedback efficiency and synergy. Climate Dyn., 41, 2539-2554, https:// doi.org/10.1007/s00382-013-1808-7.

Mitchell, J. F. B., and W. J. Ingram, 1992: Carbon dioxide and climate: Mechanisms of changes in cloud. J. Climate, 5, 5-21, https://doi.org/10.1175/1520-0442(1992)005<0005:CDACMO> 2.0.CO;2.

Norris, J. R., R. J. Allen, A. T. Evan, M. D. Zelinka, C. W. O’Dell, and S. A. Klein, 2016: Evidence for climate change in the satellite cloud record. Nature, 536, 72-75, https://doi.org/ 10.1038/nature18273.

Pithan, F., and T. Mauritsen, 2014: Arctic amplification dominated by temperature feedbacks in contemporary climate models. Nat. Geosci., 7, 181-184, https://doi.org/10.1038/ ngeo2071.

Scheff, J., and D. M. W. Frierson, 2012: Robust future precipitation declines in CMIP5 largely reflect the poleward expansion of model subtropical dry zones. Geophys. Res. Lett., 39, L18704, https://doi.org/10.1029/2012GL052910.

Schneider, T., 2006: The general circulation of the atmosphere. Annu. Rev. Earth Planet. Sci., 34, 655-688, https://doi.org/ 10.1146/annurev.earth.34.031405.125144.
Seidel, D. J., Q. Fu, W. J. Randel, and T. J. Reichler, 2008: Widening of the tropical belt in a changing climate. Nat. Geosci., 1, 21-24, https://doi.org/10.1038/ngeo.2007.38.

Shaw, T. A., and Z. Tan, 2018: Testing latitudinally dependent explanations of the circulation response to increased $\mathrm{CO}_{2}$ using aquaplanet models. Geophys. Res. Lett., 45, 9861-9869, https://doi.org/10.1029/2018GL078974.

— influences of climate change. Nat. Geosci., 9, 656-664, https:// doi.org/10.1038/ngeo2783.

Shepherd, T. G., 2014: Atmospheric circulation as a source of uncertainty in climate change projections. Nat. Geosci., 7, 703708, https://doi.org/10.1038/ngeo2253.

Singh, M. S., and P. A. O'Gorman, 2012: Upward shift of the atmospheric general circulation under global warming: Theory and simulations. J. Climate, 25, 8259-8276, https://doi.org/ 10.1175/JCLI-D-11-00699.1.

Stevens, B., and S. Bony, 2013: Water in the atmosphere. Phys. Today, 66, 29-34, https://doi.org/10.1063/PT.3.2009.

,$- \ldots$, and M. Webb, 2012: Clouds On-Off Klimate Intercomparion Experiment (COOKIE). EUCLIPSE, accessed 22 April 2019, http://www.euclipse.eu/wp4/wp4.html.

_- and Coauthors, 2013: Atmospheric component of the MPI-M Earth System Model: ECHAM6. J. Adv. Model. Earth Syst., 5, 146-172, https://doi.org/10.1002/jame.20015.

Taylor, K. E., R. J. Stouffer, and G. A. Meehl, 2012: An overview of CMIP5 and the experiment design. Bull. Amer. Meteor. Soc., 93, 485-498, https://doi.org/10.1175/BAMS-D-11-00094.1.

Tegen, I., P. Hollrig, M. Chin, I. Fung, D. Jacob, and J. Penner, 1997: Contribution of different aerosol species to the global aerosol extinction optical thickness: Estimates from model results. J. Geophys. Res., 102, 23 895-23 915, https://doi.org/ 10.1029/97JD01864.

Thompson, D. W. J., S. Bony, and Y. Li, 2017: Thermodynamic constraint on the depth of the global tropospheric circulation. Proc. Natl. Acad. Sci. USA, 114, 8181-8186, https://doi.org/ 10.1073/pnas.1620493114.

Vial, J., J.-L. Dufresne, and S. Bony, 2013: On the interpretation of inter-model spread in CMIP5 climate sensitivity estimates. Climate Dyn., 41, 3339-3362, https://doi.org/10.1007/s00382-013-1725-9.

Voigt, A., and T. Shaw, 2015: Circulation response to warming shaped by radiative changes of clouds and water vapor. Nat. Geosci., $\mathbf{8}$, 102-106, https://doi.org/10.1038/ngeo2345.

$\longrightarrow$, and - 2016: Impact of regional atmospheric cloudradiative changes on shifts of the extratropical jet stream in response to global warming. J. Climate, 29, 8399-8421, https:// doi.org/10.1175/JCLI-D-16-0140.1.

_- and Coauthors, 2017: Fast and slow shifts of the zonal-mean intertropical convergence zone in response to an idealized anthropogenic aerosol. J. Adv. Model. Earth Syst., 9, 870-892, https://doi.org/10.1002/2016MS000902.

Watt-Meyer, O., and D. M. W. Frierson, 2017: Local and remote impacts of atmospheric cloud radiative effects onto the eddy-driven jet. Geophys. Res. Lett., 44, $10036-10044$, https://doi.org/10.1002/2017GL074901.

Webb, M. J., and Coauthors, 2017: The Cloud Feedback Model Intercomparison Project (CFMIP) contribution to CMIP6. Geosci. Model Dev., 10, 359-384, https://doi.org/10.5194/gmd10-359-2017.

Wendisch, M., P. Yang, and P. Pilewskie, 2007: Effects of ice crystal habit on thermal infrared radiative properties and forcing of cirrus. J. Geophys. Res., 112, D08201, https://doi.org/10.1029/ 2006JD007899. 
Wetherald, R. T., and S. Manabe, 1988: Cloud feedback processes in a general circulation model. J. Atmos. Sci., $\mathbf{4 5}$, 1397-1416, https://doi.org/10.1175/1520-0469(1988)045<1397: CFPIAG $>2.0 . \mathrm{CO} ; 2$

Yin, J. H., 2005: A consistent poleward shift of the storm tracks in simulations of 21st century climate. Geophys. Res. Lett., 32, L18701, https://doi.org/10.1029/2005GL023684.

Yuval, J., and Y. Kaspi, 2016: Eddy activity sensitivity to changes in the vertical structure of baroclinicity. J. Atmos. Sci., 73, 1709 1726, https://doi.org/10.1175/JAS-D-15-0128.1.
Zängl, G., D. Reinert, P. Ripodas, and M. Baldauf, 2015: The ICON (ICOsahedral Non-hydrostatic) modelling framework of DWD and MPI-M: Description of the non-hydrostatic dynamical core. Quart. J. Roy. Meteor. Soc., 141, 563-579, https:// doi.org/10.1002/qj.2378.

Zelinka, M. D., S. A. Klein, K. E. Taylor, T. Andrews, M. J. Webb, J. M. Gregory, and P. M. Forster, 2013: Contributions of different cloud types to feedbacks and rapid adjustments in CMIP5. J. Climate, 26, 5007-5027, https://doi.org/10.1175/ JCLI-D-12-00555.1. 